\title{
Phosphoproteomic analysis of aged skeletal muscle
}

\author{
JOAN GANNON, LISA STAUNTON, KATHLEEN O'CONNELL, PHILIP DORAN and KAY OHLENDIECK \\ Department of Biology, National University of Ireland, Maynooth, Co. Kildare, Ireland
}

Received February 27, 2008; Accepted April 4, 2008

\begin{abstract}
One of the most important post-translational modifications is represented by phosphorylation on tyrosine, threonine and serine residues. Since abnormal phosphorylation is associated with various pathologies, it was of interest to perform a phosphoproteomic profiling of age-related skeletal muscle degeneration. We used the fluorescent phosphospecific Pro-Q Diamond dye to determine whether changes in the overall phosphorylation of the soluble skeletal muscle proteome differs significantly between young adult and senescent fibres. As an established model system of sarcopenia, we employed 30-month-old rat gastrocnemius fibres. Following the mass spectrometric identification of 59 major 2-D phosphoprotein landmark spots, the fluorescent dye staining survey revealed that 22 muscle proteins showed a differential expression pattern between 3-month- and 30-month-old muscle. Increased phosphorylation levels were shown for myosin light chain 2 , tropomyosin $\alpha$, lactate dehydrogenase, desmin, actin, albumin and aconitase. In contrast, decreased phospho-specific dye binding was observed for cytochrome c oxidase, creatine kinase and enolase. Thus, aging-induced alterations in phosphoproteins appear to involve the contractile machinery and the cytoskeleton, as well as the cytosolic and mitochondrial metabolism. This confirms that sarcopenia of old age is a complex neuromuscular pathology that is associated with drastic changes in the abundance and structure of key muscle proteins.
\end{abstract}

\section{Introduction}

Since each mammalian gene may generate more than one protein species, the approximately 30,000 human genes probably express hundred thousands of different proteins (1).

Correspondence to: Professor Kay Ohlendieck, Department of Biology, National University of Ireland, Maynooth, Co. Kildare, Ireland

E-mail:kay.ohlendieck@nuim.ie

Abbreviations: CCB, colloidal Coomassie Blue; MALDI, matrixassisted laser desorption/ionization; RuBPs, ruthenium bathophenathroline disulfonate chelate; ToF, time-of-flight

Key words: aging, phosphoproteome, phosphorylation, skeletal muscle, sarcopenia, proteomics
Thus, proteomics research has a central place in modern biology and biomedicine enabling us to understand the enormously complex and dynamic protein expression patterns in the various mammalian and human cell types (2-4). Since post-translational modifications play a crucial role in protein diversity, various sub-disciplines of proteomics have emerged that focus on the cataloguing and functional characterization of proteins with extensively modified site chains (5-7), including phosphoproteins (8-12). Post-translational modifications are key modulators of protein structure, function, signaling and regulation, whereby phosphorylation represents one of the most frequent peptide modifications. Based on the results of a recent mass spectrometric study, it can be assumed that a large portion of proteins encoded by mammalian genomes are phosphorylated at more than one residue (13). Most phosphate groups are linked to the hydroxy group of serine or threonine, in addition to tyrosine and various rare amino acids (14). The biological importance of reversible phosphorylation is emphasized by the large number of genes encoding the protein families of protein kinases and phosphatases $(15,16)$. Complex co-operations between various classes of kinases and phosphatases underlie the dynamics of phosphorylation cycles, which are especially involved in signaling pathways $(17,18)$.

Over the last few years, skeletal muscle proteomics has established itself as an important analytical tool for studying normal and pathological aspects of modern myology (19-21). Comprehensive proteomic maps exist for various species including human skeletal muscle $(22,23)$ and the most common animals used in biomedical studies of neuromuscular diseases $(21,24,25)$. Recent mass spectrometry-based proteomic profiling studies of skeletal muscle have revealed the protein biochemical basis of important physiological processes, such as the differential protein expression pattern in slow versus fast fibers (26-28) and the stimulation-induced changes during the fast-to-slow transition process $(29,30)$. Proteomics was instrumental in the establishment of new biomarkers of myoblast differentiation (31) and muscle growth (32,33), as well as the biochemical identification of disease markers that are characteristic for X-linked muscular dystrophy $(34,35)$, dysferlinopathy (36) and immobilization-induced muscular atrophy (37). Since aging also severely affects the performance of skeletal muscle fibres (38), proteomics has been applied to the investigation of the complex process of aging-induced loss in skeletal muscle mass and function (39-42).

Although proteomic studies on human muscle aging have been successfully carried out (40), inter-individual differences between patients make the interpretation of human proteomic 
data often difficult (43). In contrast, inbred animal strains show genetically much less variations, therefore considerably lower experimental repeats can produce meaningful pathobiochemical results (21). Animal model proteomics can be conveniently used to identify novel biomarkers of muscle diseases and for studying basic mechanisms of molecular pathogenesis. With respect to sarcopenia of old age, 30-monthold rat skeletal muscle is a commonly employed model system of aging-induced muscle wasting (44). Proteomic profiling of senescent rat muscle has been performed with Coomassie staining (39), fluorescent Deep Purple labeling (41) and fluorescent difference in-gel electrophoresis (42). The main findings of these studies agree with the idea that altered protein expression occurs during aging in protein species that are involved in contraction, metabolism, ion homeostasis and stress response (38). In agreement with proteomic findings (39-42), a recent cell biological study of major muscle stress proteins has confirmed that the abundance of the small heat shock proteins cvHsp/HspB5 and $\alpha \mathrm{B}$-crystallin/HspB7 is greatly increased in aged muscle fibres (45), possibly representing an auto-protective mechanism to extreme cellular stress in senescent muscle (46).

Here, we used a combination of two-dimensional gel electrophoresis, phospho-specific fluorescent Pro-Q Diamond staining (47-51) and mass spectrometric analysis in order to uncover potential age-dependent alterations in muscle protein phosphorylation. Following the initial determination of abundant 2-D gel electrophoretic landmark phosphoproteins from the soluble skeletal muscle proteome, a quantitative comparison of phosphoproteins in young adult versus old muscle fibres was performed. The analysis revealed that 22 proteins appear to exhibit major changes in their phosphorylation moieties during muscle aging. Peptide mass fingerprinting showed that members of this cohort of muscle phosphoproteins belong to the contractile apparatus, the cytoskeletal network, major cytosolic pathways and mitochondrial metabolism. Since altered phosphorylation patterns were found in proteins involved in a great variety of biological functions, it is reasonable to assume that these alterations in post-translational modifications may be involved in the functional decline of senescent fibres.

\section{Materials and methods}

Materials. Pro-Q Diamond Phosphoprotein Gel Stain (Molecular Probes, Eugene, OR, USA) was purchased from BioSciences Ltd., Dun Laoghaire, Ireland. Electrophoresis grade chemicals, immobilized $\mathrm{pH}$ gradient strips of $\mathrm{pH} 3.0$ 10.0 and IPG buffer of $\mathrm{pH}$ 3.0-10.0 for isoelectric focusing, the 2-D Quant kit and acetonitrile were from GE Healthcare (Little Chalfont, Bucks, UK). Ultrapure Protogel acrylamide stock solutions were from National Diagnostics (Atlanta, GA, USA), and sequencing grade-modified trypsin was obtained from Promega (Madison, WI, USA). A matrix kit containing $\alpha$-cyano-4-hydroxycinnamic acid and the external peptide MS calibration kit Peptidemix-1 were from Laserbiolabs (Sophia-Antipolis, France). Protease inhibitors were purchased from Roche Diagnostics GmbH (Mannheim, Germany). All other chemicals used were of analytical grade and obtained from Sigma Chemical Co. (Dorset, UK).
Preparation of protein extracts from skeletal muscle. The phosphoproteomic study described here was performed with 3-month old versus 30-month-old rat gastrocnemius muscle preparations, whereby 30-month-old Wister rats represent an established animal model of sarcopenia of old age $(39,41)$. Freshly dissected tissue samples from young adult versus senescent animals were obtained from the Bioresource Facility of the Physiology Department, Trinity College Dublin. Rat colonies were kept at a standard light dark cycle and fed ad libitum (42). Both animal populations employed in this study were not specifically trained, but were unrestricted in their movement in standard animal house cages, whereby the older rat population had a reduced activity level as compared to the younger cohort (45). Skeletal muscle samples were immediately quick-frozen in liquid nitrogen and ground into a fine powder using a pestle and mortar. For comparative studies, equal amounts of young adult versus aged muscle preparations (100 mg wet weight) were used. Muscle powder was resuspended in $1 \mathrm{ml}$ of lysis buffer, containing $20 \mathrm{mM}$ Tris, $7 \mathrm{M}$ urea, $2 \mathrm{M}$ thiourea, $65 \mathrm{mM}$ Chaps, $1 \%$ (v/v) Ampholytes pH 3.0-10.0 and $10 \mathrm{mg} / \mathrm{ml}$ DTT. In order to eliminate excessive viscocity due to the presence of large quantities of DNA, $10 \mu 1$ of DNase-I (200 units) was added per $1 \mathrm{ml}$ of lysis buffer (35). In addition, the lysis buffer was supplemented with a protease inhibitor cocktail $(0.2 \mathrm{mM}$ pefabloc, $1.4 \mathrm{mM}$ pepstatin, $0.15 \mathrm{mM}$ aprotinin, $0.3 \mathrm{mM} \mathrm{E}-64$, $1 \mathrm{mM}$ leupetin, $0.5 \mathrm{mM}$ soybean trypsin inhibitor and $1 \mathrm{mM}$ EDTA) to avoid proteolytic degradation of sensitive skeletal muscle proteins (29). Following incubation for $3 \mathrm{~h}$ at room temperature, with gentle vortexing every $10 \mathrm{~min}$ for $30 \mathrm{sec}$, the suspension was centrifuged at $4^{\circ} \mathrm{C}$ for $20 \mathrm{~min}$ at $20,000 \mathrm{x} \mathrm{g}$. The protein-containing middle layer was carefully removed. Since excess lipids, salts and nucleic acids may interfere with the proper two-dimensional gel electrophoretic separation of extracted proteins; these substances were removed prior to isoelectric focusing by acetone precipitation, as previously described in detail (35). Precipitated muscle proteins were resuspended in standard lysis buffer, and the protein concentration was determined using the 2-D Quant kit.

Two-dimensional gel electrophoresis. The two-dimensional gel electrophoretic separation of the soluble protein complement from young adult versus senescent skeletal muscle was carried out by standard procedures $(30,35,42)$, using a total protein amount of $400 \mu \mathrm{g}$ per gel. Using a reswelling tray from GE Healthcare, IPG strips $\mathrm{pH}$ 3.0-10.0 (linear) were rehydrated for $12 \mathrm{~h}$ with $0.45 \mathrm{ml}$ of a buffer containing $20 \mathrm{mM}$ Tris, $7 \mathrm{M}$ urea, $2 \mathrm{M}$ thiourea, $65 \mathrm{mM}$ Chaps, $1 \%(\mathrm{v} / \mathrm{v})$ Ampholytes pH 3.0-10.0 and $10 \mathrm{mg} / \mathrm{ml}$ DTT). As a tracking dye, the buffer was complemented with $0.05 \%$ (w/v) Bromophenol blue. Following placement of the first-dimension strips gel-side up into the Ettan IPGphor manifold and coverage with $108 \mathrm{ml}$ of dry-strip cover fluid, protein samples were loaded by aniodic cup loading, and were then run on the IPGphor IEF system from GE Healthcare. The following isoelectric focusing running conditions were used: $120 \mathrm{~min}$ at $300 \mathrm{~V}$ (step-and-hold), $150 \mathrm{~min}$ at $500 \mathrm{~V}$ (step-and-hold), $60 \mathrm{~min}$ at $1000 \mathrm{~V}$ (gradient), $60 \mathrm{~min}$ at $2000 \mathrm{~V}$ (gradient), $60 \mathrm{~min}$ at $4000 \mathrm{~V}$ (gradient), $60 \mathrm{~min}$ at $6000 \mathrm{~V}$ (gradient), $60 \mathrm{~min}$ at $8000 \mathrm{~V}$ (gradient), $180 \mathrm{~min}$ at $500 \mathrm{~V}$ 
(step-and-hold) and $120 \mathrm{~min}$ at $8000 \mathrm{~V}$ (step-and hold). Following first-dimension separation, gel strips were equilibrated for $30 \mathrm{~min}$ in the above described buffer containing $100 \mathrm{mM}$ dithiothreitol followed by another $30 \mathrm{~min}$ of equilibration with the buffer being supplemented with $0.25 \mathrm{M}$ ideoacetamide (42). Using the Ettan Dalt-Twelve system from GE Healthcare, the gel electrophoretic separation of muscle proteins in the second dimension was performed with standard $12.5 \%$ SDS-PAGE resolving gels (30). Following a brief washing in SDS-containing running buffer, isoelectric focusing strips were positioned on top of the seconddimension slab gel with the help of a $1 \%(\mathrm{w} / \mathrm{v})$ agarose sealing gel. Twelve slab gels were run in parallel at $0.5 \mathrm{~W} / \mathrm{gel}$ for $60 \mathrm{~min}$ and then at $15 \mathrm{~W} / \mathrm{gel}$ for $4.5 \mathrm{~h}$ until the blue dye front had just disappeared from the bottom of the gel.

Pro-Q Diamond gel staining and multiplex image analysis. Fluorescent staining of slab gels using the Pro-Q Diamond phosphoprotein gel stain was carried out by an optimized procedure, which was based on published protocol and the manufacturer's recommendations (47-51). Gels were fixed overnight in $50 \%(\mathrm{v} / \mathrm{v})$ methanol, $10 \%(\mathrm{v} / \mathrm{v})$ trichloroacetic acid and then fixed again in a fresh solution for $60 \mathrm{~min}$, whereby a minimum of 11 fixation solution was used per slab gel. Following wash steps with four changes of distilled water for $15 \mathrm{~min}$, gels were incubated in parallel with the undiluted fluorescent dye for $4 \mathrm{~h}$ in the dark. De-staining was achieved with four successive washes using $4 \%(\mathrm{w} / \mathrm{v})$ acetonitrile in $50 \mathrm{mM}$ sodium acetate, $\mathrm{pH}$ 4.0. Reproducible images can be obtained $\sim 4 \mathrm{~h}$ after staining. Fluorescently labeled proteins were visualized using the Typhoon Trio variable mode imager system from GE Healthcare. Images were scanned using a 532-nm laser with a PMT value for all scanned images of 600 . Prior to analysis, gel images were cropped using the Image-Quant TL software programme. All gels were scanned at $100 \mathrm{~mm}$ resolution. Following image acquisition of Pro-Q Diamond labeled protein spots, slab gels were stained for total protein with the dye Ruthenium II Bathophenathroline Disulfonate Chelate (RuBPs), which permitted direct comparison of the phosphoprotein cohort with the total muscle protein profile. A stock solution of RuBPs dye was prepared as described previously by Rabilloud and co-workers (52). Following two washings for $5 \mathrm{~min}$, gels were stained for $6 \mathrm{~h}$ in $20 \%(\mathrm{v} / \mathrm{v})$ ethanol containing $200 \mathrm{nM}$ of ruthenium chelate. Gels were re-equilibrated twice for $10 \mathrm{~min}$ in distilled water prior to imaging. Gel analysis was performed with the Image Master Platinum 5 analysis software package. Protein spots that showed a drastic increase or decrease were then identified using mass spectrometric fingerprinting analysis (20).

Mass spectrometric fingerprinting analysis. The mass spectrometric identification of skeletal muscle proteins of interest was performed with colloidal Coomassie-stained two-dimensional pick gels, matched to the Pro-Q Diamond labeled master gel. Standard in-gel tryptic digestion was used for the generation of peptide fingerprints, and matrix-assisted laser desorption/ionization time-of-flight (MALDI-ToF) mass spectrometric analysis was performed as previously optimized by our laboratory $(29,35,41,42)$. Briefly, excised gel plugs of proteins with a drastic change in expression or phosphorylation levels were placed in presiliconised plastic tubes and then destained, desalted and washed by standard procedures (42). Protein digestion was carried out with $1 \mathrm{mg}$

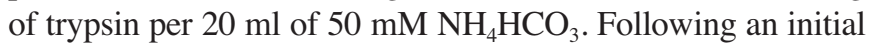
incubation step for $60 \mathrm{~min}$ at $37^{\circ} \mathrm{C}$, excess enzyme solution was removed and $10 \mu \mathrm{l}$ of $50 \mathrm{mM} \mathrm{NH} \mathrm{NCO}_{3}$ was added to each gel plug in order to keep gel pieces wet overnight (35). Peptide mixtures were then centrifuged at $12,000 \mathrm{x} \mathrm{g}$ for $10 \mathrm{~min}$, and the resulting supernatant was carefully removed from each incubation tube and placed into a clean silconised plastic tube. Extracted solutions were concentrated, resuspended in $5 \mu 1$ of $3 \%(\mathrm{v} / \mathrm{v})$ trifluoroacetic acid and analysed by MALDI-ToF mass spectrometry (42). Following desalting, tryptic peptides from individual muscle protein spots were eluted onto the sample plate with a matrix solution, consisting of $5 \mathrm{mg} / \mathrm{ml} \alpha$-cyano- 4 hydroxycinnamic acid in $50 \%(\mathrm{v} / \mathrm{v})$ acetonitrile/0.1\% (v/v) trifluoroacetic acid. Recording of mass spectra was conducted with an Amersham Ettan MALDI-ToF Pro instrument (GE Healthcare) operating in the positive reflector mode at the following parameters: accelerating voltage $20 \mathrm{kV}$; and pulsed extraction: on (focus mass 2500). For external and internal calibration, Peptidemix-1 from Laserbiolabs containing peaks ranging from $1046.5 \mathrm{~m} / \mathrm{z}$ to $2465.10 \mathrm{~m} / \mathrm{z}$ and trypsin autolysis peaks at $221.104 \mathrm{~m} / \mathrm{z}$ and $842.50 \mathrm{~m} / \mathrm{z}$, respectively, were employed (41). Mass spectra were analyzed with MALDI evaluation software to identify muscle protein species, using the PMF ProFound search engine for peptide mass fingerprinting (35). All certainty hits of rat gastrocnemius muscle proteins generated by the ProFound search engine were then matched against the publicly available search engine MASCOT (http://www.matrixscience.com).

\section{Results}

Mapping of high-abundance phosphoproteins in skeletal muscle using fluorescent two-dimensional phospho-sensitive ProQ Diamond labeling. Prior to the comparative gel electrophoretic analysis of the young adult versus aged skeletal muscle phosphoproteome, we determined the position of landmark proteins with a phosphorylation moiety. This analysis was carried out with the fluorescent phosphosensitive ProQ Diamond labeling method $(48,49)$, which has recently been applied in several large-scale phosphoproteomic studies (53-55). Fig. 1 shows a cohort of major soluble phosphoproteins from rat skeletal muscle, stained with colloidal Coomassie dye, that correlate to ProQ Diamondlabeled protein species, as shown in Fig. 2. It was possible to separate well-established skeletal muscle marker proteins ranging from $16.3 \mathrm{kDa}$ (cytochrome c oxidase) to $128.3 \mathrm{kDa}$ (myosin protein c) in relative molecular mass and with a pIrange of an $\sim \mathrm{pH} 4.6$ (myosin light chain) to $\mathrm{pH} 9.4$ (malate dehydrogenase). Labeling of nitrocellulose replicas of identical slab gels, which had been used for the ProQ Diamond analysis, with phospho-specific antibodies resulted in a significantly lower staining intensity (not shown). This demonstrates the superiority of the fluorescent phosphostaining method over conventional antibody-based techniques, as previously discussed (47-51). Importantly, the overall two- 


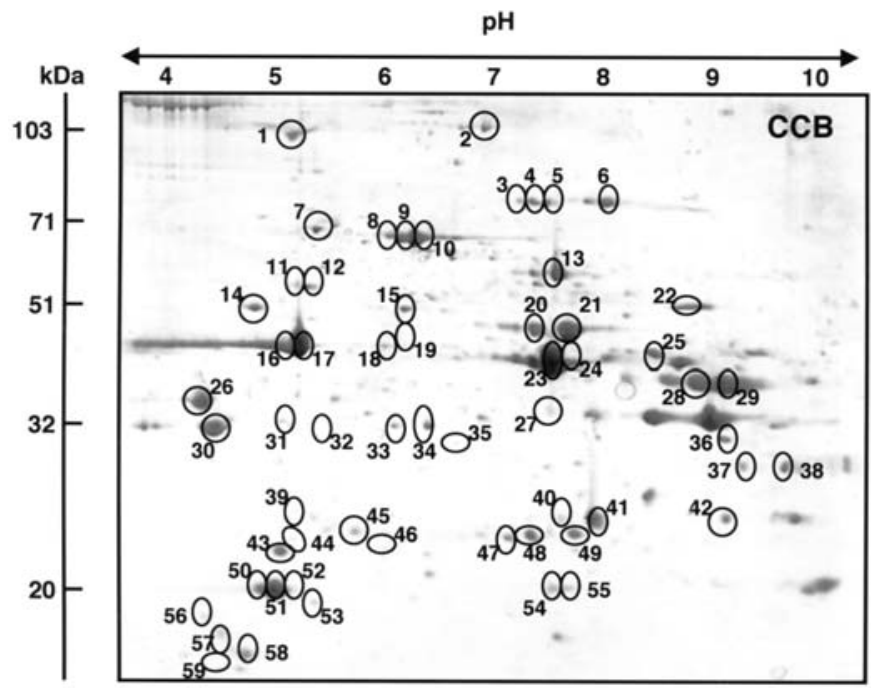

\section{Young adult}
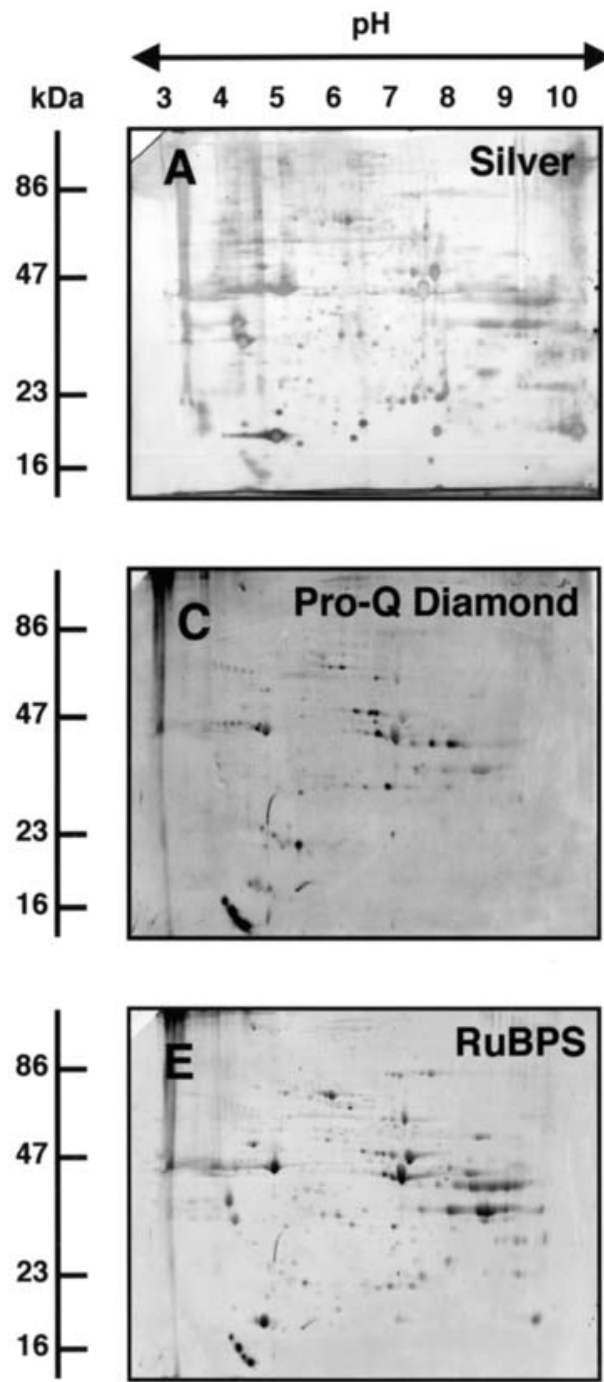

Figure 1. Two-dimensional gel electrophoretic reference gel of major phosphoproteins from rat skeletal muscle. Shown is a colloidal Coomassie Blue (CBB)-stained reference gel of 30-month-old rat skeletal muscle used for the mass spectrometric identification of proteins labeled by the fluorescent phosphoprotein-specific ProQ Diamond dye (Fig. 2C and D). Isoelectric focusing was carried out on 24-cm pH 3.0-10.0 IPG strips in the first dimension and standard $12.5 \%$ polyarcylamide slab gels in the second dimension. The $\mathrm{pH}$ values of the first dimension gel system and molecular mass standards (in $\mathrm{kDa}$ ) of the second dimension are indicated on the top and on the left of the panels, respectively. Identified proteins are marked by circles and are numbered 1-59. Table I includes a detailed listing of these landmark phosphoproteins from skeletal muscle.

\section{Senescent}
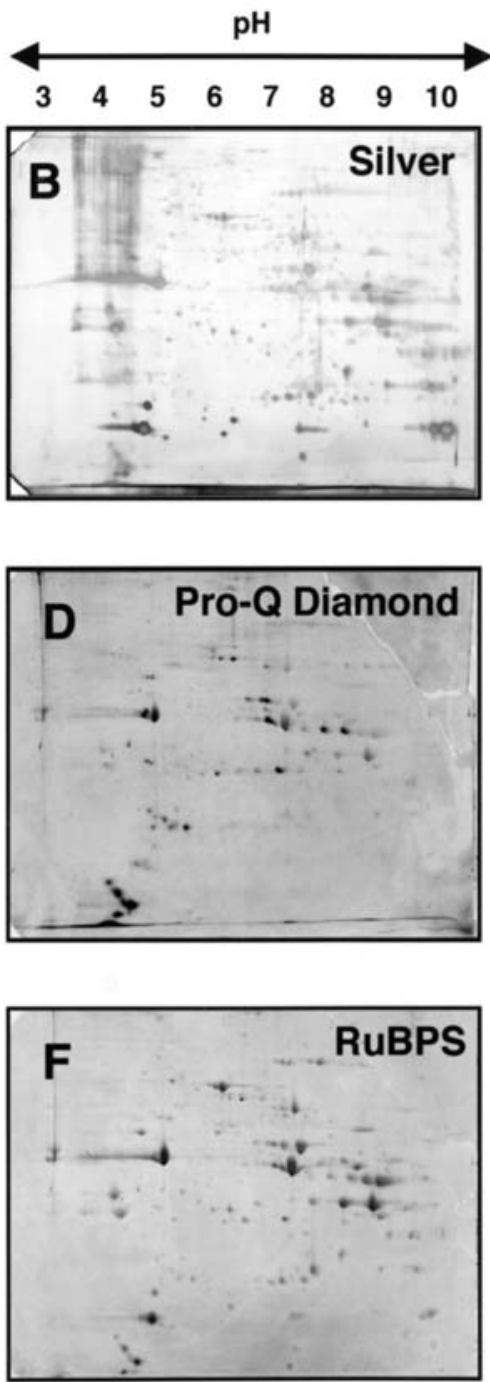

Figure 2. Comparative two-dimensional gel electrophoretic analysis of the young adult versus the aged phosphoproteome from rat skeletal muscle. Shown are two-dimensional gels labeled with silver (A and B), the fluorescent phosphoprotein gel stain Pro-Q Diamond (C and D) or the total protein dye Ruthenium II Bathophenathroline Disulfonate Chelate (RuBPs) (E and F), comparing the protein expression levels between 3-month-old (A, C and E) versus 30-month-old (B, D and F) skeletal muscle preparations. Isoelectric focusing was carried out on 24-cm pH 3.0-10.0 IPG strips in the first dimension and standard 12.5\% polyacrylamide slab gels in the second dimension. The $\mathrm{pH}$ values of the first dimension gel system and molecular mass standards (in $\mathrm{kDa}$ ) of the second dimension are indicated on the top and on the left of the panels, respectively. 


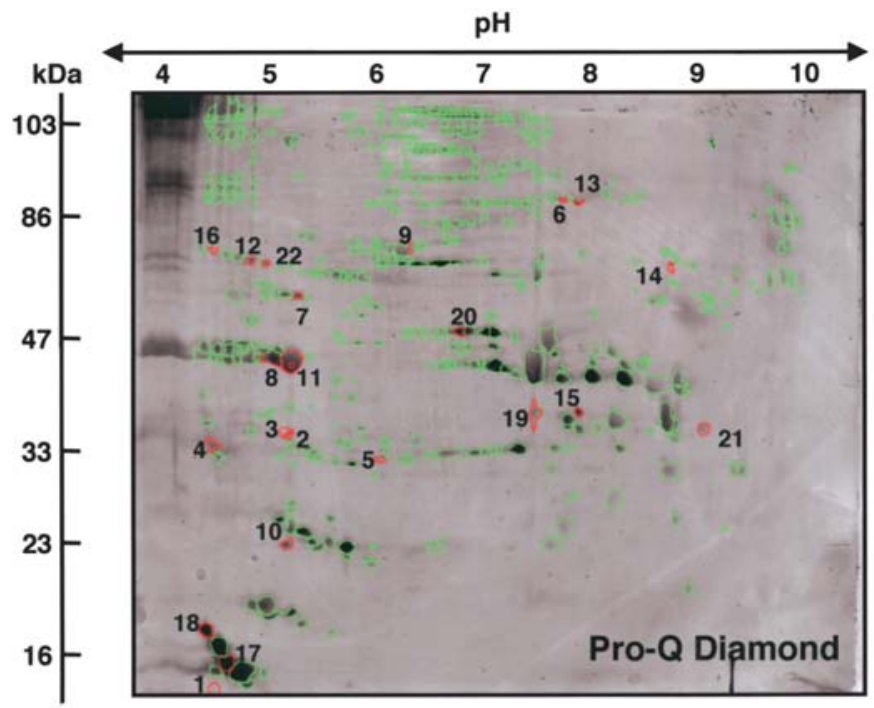

Figure 3. Two-dimensional gel electrophoretic master map of the aged skeletal muscle phosphoproteome. Shown is a two-dimensional master gel of the aged gastrocnemius muscle phosphoproteome, stained with the fluorescent phosphosprotein gel stain Pro-Q Diamond. Distinct twodimensional protein spots are marked by green borders and muscle phosphoproteins that exhibited significant changes in their abundance are indicated with red borders. Phosphoproteins with a drastically altered abundance, which have been identified by peptide mass fingerprinting analysis, are numbered 1-22, and are listed in Table II. Isoelectric focusing has been carried out on 24-cm pH 3.0-10.0 IPG strips in the first dimension and standard $12.5 \%$ polyarcylamide slab gels in the second dimension. The $\mathrm{pH}$ values of the first dimension gel system and molecular mass standards (in $\mathrm{kDa}$ ) of the second dimension are indicated on the top and on the left of the panels, respectively.

dimensional protein spot pattern of rat muscle shown in the reference gel of Fig. 1 was found to be comparable to previous studies on the electrophoretic separation of total skeletal muscle extracts. Recent reports by various proteomics research groups focusing on contractile tissue, such as Yan et al (24), Gelfi et al (27), Piec et al (39) and Doran et al (42) provide the established slab gel patterns of skeletal muscle. Following successful electrophoretic separation and ProQ Diamond labeling, abundant skeletal muscle phosphoproteins were unequivocally identified by peptide mass fingerprint analysis, using MALDI-ToF mass spectrometric screening of tryptic in-gel digests.

Identification of phosphoprotein species in skeletal muscle. As listed in Table I, fluorescent ProQ Diamond labeling identified 59 muscle phosphoprotein species that formed characteristic two-dimensional landmark spots (Fig. 1). This included major elements of the contractile apparatus (myosin heavy chain, $103.9 \mathrm{kDa} / \mathrm{pI} 5.3$; myosin light chain MLC1, $20.8 \mathrm{kDa} / \mathrm{pI} 5.0$; MLC2, $18.9 \mathrm{kDa} / \mathrm{pI} 4.8$; MLC3, $16.7 \mathrm{kDa} /$ pI 4.6; actin, $42.4 \mathrm{kDa} / \mathrm{pH} 5.2$ ) and its regulatory machinery (tropomyosin, $33.0 \mathrm{kDa} / \mathrm{pI} 4.6$ ). Major phosphorylated muscle proteins also belonged to the class of key metabolic enzymes involved in glycolysis (pyruvate kinase, $58.3 \mathrm{kDa} /$ pI 6.6; enolase, $47.4 \mathrm{kDa} / \mathrm{pI} 6.2$; aldolase, $39.8 \mathrm{kDa} / \mathrm{pI} 8.9$; lactate dehydrogenase, $30.0 \mathrm{kDa} / \mathrm{pI} 9.4$; phosphoglycerate mutase, $28.9 \mathrm{kDa} / \mathrm{pI} 9.0$; triosephosphate isomerase, $27.2 \mathrm{kDa} /$ pI 7.1); the citric acid cycle (aconitase, $86.2 \mathrm{kDa} / \mathrm{pI} 8.2$; malate dehydrogenase, $36.6 \mathrm{kDa} / \mathrm{pI} 5.9$ ); oxidative phosphorylation (ATP synthase, $51.2 \mathrm{kDa} / \mathrm{pI} 4.9$; F1-ATPase, $55.4 \mathrm{kDa} / \mathrm{pI} 8.4$; cytochrome c oxidase, $16.3 \mathrm{kDa} / \mathrm{pI} 6.1$ ); carbon dioxide removal (carbonic anhydrase, $29.7 \mathrm{kDa} / \mathrm{pI} 6.5$ ) and nucleotide metabolism (creatine kinase, $43.2 \mathrm{kDa} / \mathrm{pI} 6.6$; adenylate kinase, $21.6 \mathrm{kDa} / \mathrm{pI}$ 7.7). Landmark phosphoproteins are furthermore represented by transporters (transferrin, $78.6 \mathrm{kDa} / \mathrm{pI} 7.0$; albumin, $70.7 \mathrm{kDa} / \mathrm{pI} 6.1$; phosphatidylethanolamine binding protein, $20.9 \mathrm{kDa} / \mathrm{pI} 5.5$ ); cytoskeletal elements (desmin, $53.5 \mathrm{kDa} / \mathrm{pI} 5.2$ ); ion handling proteins (voltage dependent anion channel, $32.7 \mathrm{kDa} / \mathrm{pI} 8.5$ ) and stress proteins (Hsp72, 71.1 kDa,/pI 5.4; Hsp27, 22.9 kDa/pI 6.1; $\alpha \mathrm{B}$ crystallin, 20.1 kDa/pI 6.8).

Quantitative changes in the phosphoproteome of aged skeletal muscle. Following the establishment of a phosphoprotein reference map for rat skeletal muscle, comparative fluorescent dye staining was carried out to determine potential differences in young adult versus senescent fibres. Fig. 2 shows that the overall protein expression pattern is relatively comparable between 3-month- and 30-month-old gastrocnemius muscle. Both silver staining (Fig. 2A and B) and fluorescent RuBPs labeling ( $\mathrm{E}$ and $\mathrm{F}$ ) illustrates that most soluble muscle proteins do not exhibit massive alterations in their abundance during fibre aging. In contrast, fluorescent phospho-specific labeling, as illustrated by the representative gels shown in Fig. 2C and D, showed significant differences between the two muscle complements studied. Fig. 3 displays the phosphoproteins with an altered level of this post-translational modification as compared to the total cohort of ProQ Diamond-labeled muscle proteins. The phospho-specific survey revealed that 22 muscle protein spots exhibit a differential expression pattern between 3-month- and 30month-old gastrocnemius fibres. As listed in Table II, increased phosphorylation levels were observed for myosin light chain 2 , golgi reassembly stacking protein 1 , tropomyosin $\alpha$, lactate dehydrogenase, desmin, actin, albumin, Down syndrome critical region homolog 6 protein and aconitase, as well as 4 unidentified proteins. The fold change in phosphorylation was clearly higher for protein spot 1 , the myosin light chain isoform MLC-2, as compared to its increase in protein abundance. In contrast, decreased ProQ Diamond binding was shown for cytochrome c oxidase, creatine kinase and enolase, as well as 4 unidentified muscle components. However, direct comparison between altered phosphorylation levels and modified protein abundance of individual protein species, as listed in Table II, revealed that these two parameters do not necessarily correlate for all proteins during the muscle aging process. While the majority of muscle proteins with a decreased ProQ Diamond binding also showed a lower level of protein density, one of the unidentified proteins, spot 15 in Fig. 3, exhibited increased protein levels. Overall, the phospho-specific labeling procedure indicates that numerous skeletal muscle proteins are modified by a drastic age-dependent alteration in phosphorylation.

\section{Discussion}

Aged skeletal muscle proteins undergo considerable changes in post-translational modifications, as recently reviewed by 
Table I. Colloidal Coomassie-stained reference 2-D map of phosphorylated proteins from 30-month-old rat muscle. ${ }^{\mathrm{a}}$

\begin{tabular}{|c|c|c|c|c|c|c|}
\hline Spot no. & Name of identified proteins & $\begin{array}{c}\text { Sequence } \\
\text { coverage }(\%)\end{array}$ & $\begin{array}{l}\text { Molecular } \\
\text { mass (kDa) }\end{array}$ & $\mathrm{pI}$ & $\begin{array}{c}\text { Expectation } \\
\text { value }\end{array}$ & $\begin{array}{c}\text { Protein } \\
\text { accession no. }\end{array}$ \\
\hline 1 & Muscle myosin heavy chain & 16.0 & 103.9 & 5.3 & $6.5 \mathrm{e}-003$ & gi[71143152] \\
\hline 2 & Myosin protein c, fast-type & 27.4 & 128.3 & 6.2 & 1e-004 & gi[62639660] \\
\hline 3 & Serotransferrin precursor & 19.3 & 78.6 & 7.0 & $1 \mathrm{e}-004$ & gi[6175089] \\
\hline 4 & Serotransferrin precursor & 11.7 & 78.6 & 7.0 & $1 \mathrm{e}-004$ & gi[6175089] \\
\hline 5 & Transferrin & 12.0 & 78.6 & 7.0 & 0.030 & gi[1854476] \\
\hline 6 & Aconitase 2, mitochondrial & 20.3 & 86.2 & 8.2 & $1 \mathrm{e}-004$ & gi[38541404] \\
\hline 7 & Hsp72-ps1 & 17.0 & 71.1 & 5.4 & $4.9 \mathrm{e}-003$ & gi[347019] \\
\hline 8 & Albumin & 28.0 & 70.7 & 6.1 & $2.2 \mathrm{e}-006$ & gi[19705431] \\
\hline 9 & Albumin & 22.0 & 70.7 & 6.1 & $8.8 \mathrm{e}-004$ & gi[55391508] \\
\hline 10 & Albumin & 35.0 & 70.7 & 6.1 & $2.5 \mathrm{e}-006$ & gi[55391508] \\
\hline 11 & Desmin & 16.0 & 53.5 & 5.2 & 1e-004 & gi[11968118] \\
\hline 12 & Desmin & 21.7 & 53.5 & 5.2 & $1 \mathrm{e}-004$ & gi[11968118] \\
\hline 13 & Pyruvate kinase & 29.0 & 58.3 & 6.6 & 0.011 & gi[16757994] \\
\hline 14 & ATP synthase, $ß$ subunit & 29.7 & 51.2 & 4.9 & $1 \mathrm{e}-004$ & gi[1374715] \\
\hline 15 & Enolase $1, \alpha$ & 25.0 & 47.4 & 6.2 & 0.021 & gi[6978809] \\
\hline 16 & $\alpha 1$ actin, skeletal muscle & 21.0 & 42.4 & 5.2 & 0.057 & gi[54036667] \\
\hline 17 & $\alpha$ actin & 21.0 & 42.4 & 5.2 & $2.3 e-004$ & gi[54036667] \\
\hline 18 & $\alpha$ actin (aa27-375) & 15.8 & 39.5 & 5.8 & $1 \mathrm{e}-004$ & gi[49871] \\
\hline 19 & Hemogen & 20.0 & 54.1 & 5.4 & 0.070 & gi[19882215] \\
\hline 20 & Enolase 3, ß & 36.0 & 47.3 & 7.1 & $3.7 \mathrm{e}-004$ & gi[54035288] \\
\hline 21 & Enolase $3, \beta$ & 35.0 & 47.3 & 7.1 & $4.8 \mathrm{e}-003$ & gi[54035288] \\
\hline 22 & F1 ATPase, chain A & 23.0 & 55.4 & 8.4 & $7.9 \mathrm{e}-003$ & gi[6729934] \\
\hline 23 & Creatine kinase & 24.0 & 33.4 & 8.0 & $2.3 \mathrm{e}-003$ & gi[203480] \\
\hline 24 & Creatine kinase, chain $\mathrm{M}$ & 28.0 & 43.2 & 6.6 & $4.8 \mathrm{e}-004$ & gi[6978661] \\
\hline 25 & Creatine kinase, mitochondrial & 21.0 & 47.8 & 9.2 & 0.075 & gi[125313] \\
\hline 26 & Tropomyosin 1 & 24.0 & 33.0 & 4.6 & $1.8 \mathrm{e}-004$ & gi[207498] \\
\hline 27 & Creatine kinase & 33.0 & 43.3 & 6.6 & $1.6 \mathrm{e}-004$ & gi[38541353] \\
\hline 28 & Aldolase A & 30.0 & 39.8 & 8.9 & 0.015 & gi[3978487] \\
\hline 29 & Aldolase A & 30.0 & 39.8 & 8.9 & $5.7 e-004$ & gi[3978487] \\
\hline 30 & Tropomyosin $\alpha$ & 17.0 & 32.7 & 4.7 & $1 \mathrm{e}-004$ & gi[207349] \\
\hline 31 & Golgi reassembly stacking protein 1 & 7.0 & 48.1 & 4.6 & 0.032 & gi[9506751] \\
\hline 32 & Protein phosphatase $1 \mathrm{H}$ & 18.0 & 19.4 & 5.7 & 0.025 & gi[56789214] \\
\hline 33 & Lactate dehydrogenase & 16.0 & 36.9 & 5.7 & 0.016 & gi[6981146] \\
\hline 34 & Malate dehydrogenase & 21.0 & 36.6 & 6.2 & $1 \mathrm{e}-004$ & gi[15100179] \\
\hline 35 & Malate dehydrogenase & 26.9 & 36.6 & 5.9 & $1.9 \mathrm{e}-003$ & gi[37590235] \\
\hline 36 & Lactate dehydrogenase A & 24.0 & 30.0 & 9.4 & $1 \mathrm{e}-004$ & gi[38014570] \\
\hline 37 & Voltage dependent anion channel & 32.9 & 32.7 & 8.5 & $1 \mathrm{e}-004$ & gi[4105605] \\
\hline 38 & Malate dehydrogenase & 24.0 & 36.1 & 9.4 & $1.2 \mathrm{e}-003$ & gi[42476181] \\
\hline 39 & CD3 antigen $\delta$ polypeptide & 25.0 & 19.6 & 5.9 & 0.042 & gi[7709998] \\
\hline 40 & Carbonic anhydrase, CA3 & 28.0 & 29.7 & 6.5 & $1 \mathrm{e}-004$ & gi[203225] \\
\hline 41 & Carbonic anhydrase, CA3 & 53.5 & 29.7 & 6.9 & $1 \mathrm{e}-004$ & gi[31377484] \\
\hline 42 & Phospho glycerate mutase 2 & 34.0 & 28.9 & 9.0 & $3.8 \mathrm{e}-005$ & gi[8393948] \\
\hline 43 & Myosin, light polypeptide 3 & 43.0 & 22.3 & 5.0 & $8.8 \mathrm{e}-004$ & gi[6981240] \\
\hline 44 & Down syndrome critical region homolog 6 & 26.0 & 23.3 & 5.7 & 0.039 & gi[34865391] \\
\hline 45 & Hsp27 & 30.0 & 22.9 & 6.1 & $1 \mathrm{e}-004$ & gi[8248633] \\
\hline 46 & Myosin light chain 1 , slow & 19.0 & 27.7 & 5.8 & 0.073 & gi[34880612] \\
\hline 47 & Triosephosphate isomerase 1 & 33.5 & 27.2 & 7.1 & 1e-004 & gi[38512111] \\
\hline 48 & Triosephosphate isomerase 1 & 33.5 & 27.2 & 7.1 & $1.4 \mathrm{e}-004$ & gi[38512111] \\
\hline 49 & Triosephosphate isomerase 1 & 33.5 & 27.2 & 7.1 & $1 \mathrm{e}-004$ & gi[38512111] \\
\hline 50 & Myosin light chain 1 & 32.8 & 20.8 & 5.0 & $1 \mathrm{e}-004$ & gi[127131] \\
\hline
\end{tabular}


Table I. Continued.

\begin{tabular}{|c|c|c|c|c|c|c|}
\hline Spot no. & Name of identified proteins & $\begin{array}{c}\text { Sequence } \\
\text { coverage }(\%)\end{array}$ & $\begin{array}{l}\text { Molecular } \\
\text { mass (kDa) }\end{array}$ & $\mathrm{pI}$ & $\begin{array}{c}\text { Expectation } \\
\text { value }\end{array}$ & $\begin{array}{c}\text { Protein } \\
\text { accession no. }\end{array}$ \\
\hline 51 & Myosin light chain 1 & 27.0 & 20.8 & 5.0 & 0.015 & gi[127131] \\
\hline 52 & Myosin light chain $3 \mathrm{f}$, fast & 27.0 & 16.7 & 4.6 & $1 \mathrm{e}-004$ & gi[13487933] \\
\hline 53 & Phosphatidylethanolamine binding protein & 26.0 & 20.9 & 5.5 & 0.016 & gi[8393910] \\
\hline 54 & $\alpha \mathrm{B}$ Crystallin & 45.0 & 20.1 & 6.8 & 0.042 & gi[16905067] \\
\hline 55 & Adenylate kinase & 51.0 & 21.6 & 7.7 & $1.8 \mathrm{e}-004$ & gi[8918488] \\
\hline 56 & Cytochrome c oxidase, subunit Va & 41.0 & 16.3 & 6.1 & 0.079 & gi[24233541] \\
\hline 57 & Cytochrome c oxidase, subunit Va & 41.0 & 16.3 & 6.1 & 0.042 & gi[24233541] \\
\hline 58 & Myosin light chain 2 & 38.0 & 18.9 & 4.8 & 0.052 & gi[127167] \\
\hline 59 & Myosin light chain 2 & 40.0 & 19.1 & 4.8 & 0.011 & gi[6981238] \\
\hline
\end{tabular}

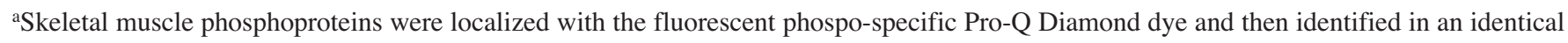
Coomassie-labeled 2-D gel by MALDI-ToF MS analysis.

Table II. List of muscle proteins that exhibit a drastic age-dependent change in phosphorylation as judged by fluorescent phospo-specific Pro-Q Diamond labeling. ${ }^{a}$

\begin{tabular}{|c|c|c|c|c|}
\hline Spot no. & Name of identified proteins & Protein accession no. & $\begin{array}{l}\text { Phosphorylation } \\
\text { fold change }(+/-)\end{array}$ & $\begin{array}{l}\text { Protein fold } \\
\text { change }(+/-)\end{array}$ \\
\hline 1 & Myosin light chain 2 & gi[6981238] & +28.48 & +9.15 \\
\hline 2 & Unidentified & - & +5.12 & n.d. \\
\hline 3 & Golgi reassembly stacking protein 1 & gi[9506751] & +5.58 & n.d. \\
\hline 4 & Tropomyosin, $\alpha$ & gi[207349] & +2.50 & n.d. \\
\hline 5 & Lactate dehydrogenase & gi[6981146] & +2.41 & n.d. \\
\hline 6 & Unidentified & - & +2.30 & n.d. \\
\hline 7 & Desmin & gi[11968118] & +2.22 & +2.09 \\
\hline 8 & Actin, $\alpha 1$ & gi[9506371] & +2.18 & +2.73 \\
\hline 9 & Albumin & gi[55391508] & +2.10 & n.d. \\
\hline 10 & Down sydrome critical region homolog 6 & $\operatorname{gi}[34865391]$ & +2.09 & n.d. \\
\hline 11 & Actin, $\alpha$ & gi[54036667] & +2.07 & n.d. \\
\hline 12 & Unidentified & - & +1.97 & +1.95 \\
\hline 13 & Aconitase 2 & $\operatorname{gi}[38541404]$ & +1.80 & n.d. \\
\hline 14 & Unidentified & - & +1.50 & n.d. \\
\hline 15 & Unidentified & - & -1.57 & +1.77 \\
\hline 16 & Unidentified & - & -1.70 & n.d. \\
\hline 17 & Cytochrome c oxidase & gi[24233541] & -1.89 & n.d. \\
\hline 18 & Cytochrome c oxidase & gi[24233541] & -2.05 & n.d. \\
\hline 19 & Creatine kinase & gi[38541353] & -2.25 & n.d. \\
\hline 20 & Enolase $3, \beta$ & gi[54035288] & -2.50 & -2.50 \\
\hline 21 & Unidentified & - & -3.52 & -2.03 \\
\hline 22 & Unidentified & - & -5.75 & n.d. \\
\hline
\end{tabular}

${ }^{a}$ The young adult (3-month-old) versus senescent (30-month-old) rat skeletal muscle proteome was differentially labeled with the fluorescent phospo-specific Pro-Q Diamond dye and the protein stain RuBPS, followed by the identification of proteins with a drastic change in phosphorylation by MALDI-ToF MS analysis (n.d., not detectable).

Schoneich (56). For example, the nitration of protein tyrosine residues represents an important post-translational modification during biological aging (44). This has been especially well documented for the sarcoplasmic reticulum $\mathrm{Ca}^{2+}$ -
ATPase (57) and glycogen phosphorylase b (58). Reduced activity of the SERCA-type $\mathrm{Ca}^{2+}$-pump as a result of the nitration of selected tyrosines appears to play a key role in the pathophysiological increase in intracellular $\mathrm{Ca}^{2+}$ levels within 
senescent skeletal muscle fibres (59). Comprehensive proteomic studies by Kanski et al $(44,60)$ have identified an age-related increase in the nitration of numerous other skeletal muscle proteins. This includes enolase, aldolase, creatine kinase, tropomyosin, glyceraldehyde-3-phosphate dehydrogenase, myosin light chain, pyruvate kinase, actinin, actin and the ryanodine receptor. The nitration of these essential muscle proteins may therefore be a significant factor responsible for the age-related decline in muscle strength (56).

In analogy to these studies on age-related post-translational modifications, we used here gel electrophoretic separation, labeling with phospho-specific fluorescent Pro-Q Diamond stain and mass spectrometric analysis to identify muscle proteins with an altered phosphorylation pattern. Reversible protein phosphorylation plays a central role in the activity, regulation, structure and localization of proteins (18). It is estimated that more than one-third of the proteome of a typical mammalian cell is phosphorylated (13). Since skeletal muscle aging is associated with a drastic decline in muscle mass and strength (38), it was of interest to determine whether the overall phosphorylation levels of the soluble muscle proteome were altered by the aging process. Comparative phospho-specific dye staining of two-dimensional gels representing young adult versus senescent muscle revealed that a small number of muscle proteins appear to be altered with respect to their phosphorylation levels.

The most drastic increase in phosphorylation occurred in the contractile element MLC2. In addition, actin and tropomyosin also showed increased phosphorylation levels. Transitions in fibre types are associated with major changes in the abundance and isoform expression pattern of both myosin light and heavy chains $(61,62)$. The results from a recent proteomic study using fluorescent difference in-gel electrophoresis agree with the protein analysis presented here and have also shown an increased density of the MLC2 form of the myosin light chain in aged rat gastrocnemius muscle (42). It has previously been documented that the natural aging process influences fibre type proportions, fibre size and contractile properties (63). In aged rat skeletal muscle, the loss of whole motor units causes a decrease in the overall number of fibres (64), and cycles of denervation and reinnervation lead to the incomplete recruitment of senescent fibres (65). Thus, altered expression levels and/or post-translational modifications in contractile proteins are an indication that aged motor units exhibit severely altered physiological properties. Cutlip and co-workers (66) have demonstrated that age impairs the ability of rat muscle to properly adapt to repetitive mechanical loading, which agrees with the idea that aged skeletal muscles have a reduced speed of contraction $(38,64)$. The altered phosphorylation of the fatty acid bindingprotein albumin, the glycolytic enzymes lactate dehydrogenase and enolase, as well as the citric acid cycle component aconitase and the mitochondrial cytochrome c oxidase may reflect changed activities of these important metabolic components in aged fibres. Changed post-translational modifications agree with previous proteomic investigations of skeletal muscle aging, which have clearly indicated a shift to more oxidative-aerobic metabolism in slower-contracting senescent fibres (39-42). In addition, changed phosphorylation of creatine kinase and desmin indicate age-related modifications of nucleotide metabolism and the cytoskeletal network of skeletal muscle, respectively. Creatine kinase has previously been shown to be affected in sarcopenia of old age (42), and its altered post-translational modifications indicate changes in the bioenergetic shuttle system of creatine phosphate units.

In conclusion, aging-induced alterations in phosphoproteins appear mostly to affect the contractile machinery, as well as enzymes associated with cytosolic and mitochondrial metabolism. Changed post-translational modifications, in addition to impaired protein synthesis rates, may play an important pathobiochemical role in sarcopenia. The underlying mechanisms of age-related muscle degeneration appear to be multi-factorial, but impaired protein function is of central importance for fibre wasting. It remains to be elucidated whether the main triggering factor of sarcopenia is represented by denervation or resides in the muscle tissue itself. However, it is clear that muscle aging is associated with distinct changes in one of the most important post-translational modifications found in mammalian systems, phosphorylation on tyrosine, threonine and serine residues, as shown in this study.

\section{Acknowledgements}

Research was supported by a principal investigator grant from Science Foundation Ireland (SFI-04/IN3/B614) and equipment grants were from the Irish Health Research Board (HRB-EQ/2003/3, HRB-EQ/2004/2). The authors thank Dr Marina Lynch (Department of Physiology, Trinity College, Dublin) for her generous help obtaining young adult and aged rat muscle.

\section{References}

1. Black DL: Protein diversity from alternative splicing: a challenge for bioinformatics and post-genome biology. Cell 103: 367-370, 2000 .

2. de Hoog CL and Mann M: Proteomics. Annu Rev Genomics Hum Genet 5: 267-293, 2004.

3. Cox J and Mann M: Is proteomics the new genomics? Cell 130: 395-398, 2007.

4. Cho WC: Proteomics technologies and challenges. Genomics Proteomics Bioinformatics 5: 77-85, 2007.

5. Mann $M$ and Jensen ON: Proteomic analysis of posttranslational modifications. Nat Biotechnol 21: 255-261, 2003.

6. Seo J and Lee KJ: Post-translational modifications and their biological functions: proteomic analysis and systematic approaches. J Biochem Mol Biol 37: 35-44, 2004.

7. Jensen ON: Modification-specific proteomics: characterization of post-translational modifications by mass spectrometry. Curr Opin Chem Biol 8: 33-41, 2004.

8. Kalume DE, Molina H and Pandey A: Tackling the phosphoproteome: tools and strategies. Curr Opin Chem Biol 7: 64-69, 2003.

9. Reinders J and Sickmann A: State-of-the-art in phosphoproteomics. Proteomics 5: 4052-4061, 2005.

10. Salih E: Phosphoproteomics by mass spectrometry and classical protein chemistry approaches. Mass Spectrom Rev 24: 828-846, 2005.

11. Garcia BA, Shabanowitz J and Hunt DF: Analysis of protein phosphorylation by mass spectrometry. Methods 35: 256-264, 2005.

12. Goshe MB: Characterizing phosphoproteins and phosphoproteomes using mass spectrometry. Brief Funct Genomic Proteomic 4: 363-376, 2006.

13. Olsen JV, Blagoev B, Gnad F, Macek B, Kumar C, Mortensen P and Mann M: Global, in vivo, and site-specific phosphorylation dynamics in signaling networks. Cell 127: 635-648, 2006.

14. Sickmann A and Meyer HE: Phosphoamino acid analysis. Proteomics 1: 200-206, 2001. 
15. Manning G, Whyte DB, Martinez R, Hunter T and Sudarsanam S: The protein kinase complement of the human genome. Science 298: 1912-1934, 2002.

16. Moorhead GB, Trinkle-Mulcahy L and Ulke-Lemee A: Emerging roles of nuclear protein phosphatases. Nat Rev Mol Cell Biol 8: 234-244, 2007.

17. Cohen P: The regulation of protein function by multisite phosphorylation - a 25 year update. Trends Biochem Sci 25: 596-601, 2000.

18. Cohen P: The origins of protein phosphorylation. Nat Cell Biol 4: E127-E130, 2002

19. Isfort RJ: Proteomic analysis of striated muscle. J Chromatogr B771: 155-165, 2002.

20. Doran P, Donoghue P, O'Connell K, Gannon J and Ohlendieck K: Proteomic profiling of pathological and aged skeletal muscle fibres by peptide mass fingerprinting (Review). Int J Mol Med 19: 547-564, 2007

21. Doran P, Gannon J, O'Connell K and Ohlendieck K: Proteomic profiling of animal models mimicking skeletal muscle disorders. Proteomics Clin Appl 1: 1169-1184, 2007.

22. Gelfi C, De Palma S, Cerretelli P, Begum S and Wait R: Twodimensional protein map of human vastus lateralis muscle. Electrophoresis 24: 286-295, 2003.

23. Capitanio D, Vigano A, Ricci E, Cerretelli P, Wait R and Gelfi C: Comparison of protein expression in human deltoideus and vastus lateralis muscles using two-dimensional gel electrophoresis. Proteomics 5: 2577-2586, 2005.

24. Yan JX, Harry RA, Wait R, Welson SY, Emery PW, Preedy VR and Dunn MJ: Separation and identification of rat skeletal muscle proteins using two-dimensional gel electrophoresis and mass spectrometry. Proteomics 1: 424-434, 2001.

25. Sanchez JC, Chiappe D, Converset V, Hoogland C, Binz PA, Paesano S, Appel RD, Wang S, Sennitt M, Nolan A, Cawthorne MA and Hochstrasser DF: The mouse SWISS-2DPAGE database: a tool for proteomics study of diabetes and obesity. Proteomics 1: 136-163, 2001.

26. Okumura N, Hashida-Okumura A, Kita K, Matsubae M, Takao T and Nagai K: Proteomic analysis of slow- and fasttwitch skeletal muscles. Proteomics 5: 2896-2906, 2005.

27. Gelfi C, Vigano A, De Palma S, Ripamonti M, Begum S, Cerretelli $\mathrm{P}$ and Wait R: 2-D protein maps of rat gastrocnemius and soleus muscles: a tool for muscle plasticity assessment. Proteomics 6: 321-340, 2006.

28. Bihan MC, Hou Y, Harris N, Tarelli E and Coulton GR: Proteomic analysis of fast and slow muscles from normal and kyphoscoliotic mice using protein arrays, 2-DE and MS. Proteomics 6: 4646-4661, 2006.

29. Donoghue P, Doran P, Dowling P and Ohlendieck K: Differential expression of the fast skeletal muscle proteome following chronic low-frequency stimulation. Biochim Biophys Acta 1752: 166-176, 2005.

30. Donoghue P, Doran P, Wynne K, Pedersen K, Dunn MJ and Ohlendieck K: Proteomic profiling of chronic low-frequency stimulated fast muscle. Proteomics 7: 3417-3430, 2007.

31. Kislinger T, Gramolini AO, Pan Y, Rahman K, MacLennan DH and Emili A: Proteome dynamics during C2C12 myoblast differentiation. Mol Cell Proteomics 4: 887-901, 2005.

32. Doherty MK, McLean L, Hayter JR, Pratt JM, Robertson DH, El-Shafei A, Gaskell SJ and Beynon RJ: The proteome of chicken skeletal muscle: changes in soluble protein expression during growth in a layer strain. Proteomics 4: 2082-2093, 2004.

33. Bouley J, Meunier B, Chambon C, De Smet S, Hocquette JF and Picard B: Proteomic analysis of bovine skeletal muscle hypertrophy. Proteomics 5: 490-500, 2005.

34. Ge Y, Molloy MP, Chamberlain JS and Andrews PC: Proteomic analysis of mdx skeletal muscle: great reduction of adenylate kinase 1 expression and enzymatic activity. Proteomics 3: 1895-1903, 2003.

35. Doran P, Martin G, Dowling P, Jockusch H and Ohlendieck K: Proteome analysis of the dystrophin-deficient MDX diaphragm reveals a drastic increase in the heat shock protein cvHSP. Proteomics 6: 4610-4621, 2006.

36. De Palma S, Morandi L, Mariani E, Begum S, Cerretelli P, Wait R and Gelfi C: Proteomic investigation of the molecular pathophysiology of dysferlinopathy. Proteomics 6: 379-385, 2006.

37. Isfort RJ, Wang F, Greis KD, Sun Y, Keough TW, Farrar RP, Bodine SC and Anderson NL: Proteomic analysis of rat soleus muscle undergoing hindlimb suspension-induced atrophy and reweighting hypertrophy. Proteomics 2: 543-550, 2002.
38. Edstrom E, Altun M, Bergman E, Johnson H, Kullberg S, Ramirez-Leon $\mathrm{V}$ and Ulfhake B: Factors contributing to neuromuscular impairment and sarcopenia during aging. Physiol Behav 92: 129-135, 2007.

39. Piec I, Listrat A, Alliot J, Chambon C, Taylor RG and Bechet D: Differential proteome analysis of aging in rat skeletal muscle. FASEB J 19: 1143-1145, 2005.

40. Gelfi C, Vigano A, Ripamonti M, Pontoglio A, Begum S, Pellegrino MA, Grassi B, Bottinelli R, Wait R and Cerretelli C: The human muscle proteome in aging. J Proteome Res 5: 1344-1353, 2006.

41. O'Connell K, Gannon J, Doran P and Ohlendieck K: Proteomic profiling reveals a severely perturbed protein expression pattern in aged skeletal muscle. Int J Mol Med 20: 145-153, 2007.

42. Doran P, O'Connell K, Gannon J, Kavanagh M and Ohlendieck K: Opposite pathobiochemical fate of pyruvate kinase and adenylate kinase in aged rat skeletal muscle as revealed by proteomic DIGE analysis. Proteomics 8: 364-377, 2008.

43. Cobon GS, Verrills N, Papakostopoulos P, Eastwood H and Linnane AWN: The proteomics of ageing. Biogerontology 3: 133-136, 2002.

44. Kanski J, Alterman MA and Schoneich C: Proteomic identification of age-dependent protein nitration in rat skeletal muscle. Free Radic Biol Med 35: 1229-1239, 2003.

45. Doran P, Gannon J, O'Connell K and Ohlendieck K: Aging skeletal muscle shows a drastic increase in the small heat shock proteins $\alpha \mathrm{B}$-crystallin/HspB5 and cvHsp/HspB7. Eur J Cell Biol 86: 629-640, 2007.

46. Nishimura RN and Sharp FR: Heat shock proteins and neuromuscular disease. Muscle Nerve 32: 693-709, 2005.

47. Steinberg TH, Agnew BJ, Gee KR, Leung WY, Goodman T, Schulenberg B, Hendrickson J, Beechem JM, Haugland RP and Patton WF: Global quantitative phosphoprotein analysis using multiplexed proteomics technology: Proteomics 3: 1128-1144, 2003.

48. Goodman T, Schulenberg B, Steinberg TH and Patton WF: Detection of phosphoproteins on electroblot membranes using a small-molecule organic fluorophore. Electrophoresis 25: 2533-2538, 2004

49. Schulenberg B, Goodman TN, Aggeler R, Capaldi RA and Patton WF: Characterization of dynamic and steady-state protein phosphorylation using a fluorescent phosphoprotein gel stain and mass spectrometry. Electrophoresis 25: 2526-2532, 2004.

50. Wu J, Lenchik NJ, Pabst MJ, Solomon SS, Shull J and Gerling IC: Functional characterization of two-dimensional gel-separated proteins using sequential staining. Electrophoresis 26: 225-237, 2005.

51. Stasyk T, Morandell S, Bakry R, Feuerstein I, Huck CW, Stecher G, Bonn GK and Huber LA: Quantitative detection of phosphoproteins by combination of two-dimensional difference gel electrophoresis and phosphospecific fluorescent staining. Electrophoresis 26: 2850-2854, 2005.

52. Rabilloud T, Strub JM, Luche S, van Dorsselaer A and Lunardi J: A comparison between Sypro Ruby and ruthenium II tris (bathophenanthroline disulfonate) as fluorescent stains for protein detection in gels. Proteomics 1: 699-704, 2001.

53. Liu J, Cai Y, Wang J, Zhou Q, Yang B, Lu Z, Jiao L, Zhang D, Sui S, Jiang Y, Ying W and Qian X: Phosphoproteome profile of human liver Chang's cell based on 2-DE with fluorescence staining and MALDI-ToF/ToF-MS. Electrophoresis 28: 4348-4358, 2007.

54. Eymann C, Becher D, Bernhardt J, Gronau K, Klutzny A and Hecker M: Dynamics of protein phosphorylation on Ser/Thr/Tyr in Bacillus subtilis. Proteomics 7: 3509-3526, 2007.

55. Kang TH, Bae KH, Yu MJ, Kim WK, Hwang HR, Jung H, Lee PY, Kang S, Yoon TS, Park SG, Ryu SE and Lee SC: Phosphoproteomic analysis of neuronal cell death by glutamateinduced oxidative stress. Proteomics 7: 2624-2635, 2007.

56. Schoneich C: Protein modification in aging: an update. Exp Gerontol 41: 807-812, 2006.

57. Sharov VS, Dremina ES, Galeva NA, Williams TD and Schoneich C: Quantitative mapping of oxidation-sensitive cysteine residues in SERCA in vivo and in vitro by HPLCelectrospray-tandem MS: selective protein oxidation during biological aging. Biochem J 394: 605-615, 2006.

58. Sharov VS, Galeva NA, Kanski J, Williams TD and Schoneich C: Age-associated tyrosine nitration of rat skeletal muscle glycogen phosphorylase b: characterization by HPLC-nanoelectrospray-tandem mass spectrometry. Exp Gerontol 41: 407-416, 2006. 
59. Squier TS and Bigelow DJ: Protein oxidation and agedependent alterations in calcium homeostasis. Front Biosci 5: 504-526, 2000.

60. Kanski J, Hong SJ and Schoneich C: Proteomic analysis of protein nitration in aging skeletal muscle and identification of nitrotyrosine-containing sequences in vivo by nanoelectrospray ionization tandem mass spectrometry. J Biol Chem 280 24261-24266, 2005

61. Kirschbaum BJ, Heilig A, Hartner KT and Pette D: Electrostimulation-induced fast-to-slow transitions of myosin light and heavy chains in rabbit fast-twitch muscle at the mRNA level. FEBS Lett 243: 123-126, 1989.

62. Gonzalez B, Negredo P, Hernando R and Manso R: Protein variants of skeletal muscle regulatory myosin light chain isoforms: prevalence in mammals, generation and transitions during muscle remodeling. Pflugers Arch 443: 377-386, 2002.
63. Larsson L and Edstrom L: Effects of age on enzyme-histochemical fibre spectra and contractile properties of fast- and slow-twitch skeletal muscles in the rat. J Neurol Sci 76: 69-89, 1986.

64. Edstrom L and Larsson L: Effects of age on contractile and enzyme-histochemical properties of fast- and slow-twitch single motor units in the rat. J Physiol 392: 129-145, 1987.

65. Larsson L, Ansved T, Edstrom L, Gorza L and Schiaffino S Effects of age on physiological, immunohistochemical and biochemical properties of fast-twitch single motor units in the rat. J Physiol 443: 257-275, 1991.

66. Cutlip RG, Baker BA, Geronilla KB, Kashon ML and Wu JZ: The influence of velocity of stretch and dash shortening contractions on muscle performance during chronic exposure: age effects. Appl Physiol Nutr Metab 32: 443-453, 2007. 